\title{
Lusioersily
}

\section{Development of Water-Soluble Electrospun Fibers for the Oral Delivery of Cannabinoids}

Andriotis, E. G., Chachlioutaki, K., Monou, P. K., Bouropoulos, N., Tzetzis, D., Barmpalexis, P., Chang, M. W., Ahmad, Z., \& Fatouros, D. G. (2021). Development of Water-Soluble Electrospun Fibers for the Oral Delivery of Cannabinoids. AAPS PharmSciTech, 22(1), [23]. https://doi.org/10.1208/s12249-020-01895-7

Link to publication record in Ulster University Research Portal

Published in:
AAPS PharmSciTech

Publication Status:

Published online: 05/01/2021

DOI:

10.1208/s12249-020-01895-7

Document Version

Author Accepted version

\section{General rights}

Copyright for the publications made accessible via Ulster University's Research Portal is retained by the author(s) and / or other copyright owners and it is a condition of accessing these publications that users recognise and abide by the legal requirements associated with these rights.

\section{Take down policy}

The Research Portal is Ulster University's institutional repository that provides access to Ulster's research outputs. Every effort has been made to ensure that content in the Research Portal does not infringe any person's rights, or applicable UK laws. If you discover content in the Research Portal that you believe breaches copyright or violates any law, please contact pure-support@ulster.ac.uk. 
$7 \quad{ }^{1}$ Laboratory of Pharmaceutical Technology, Department of Pharmacy, School of Health

Development of Water Soluble Electrospun Fibers for the Oral Delivery of

\section{Cannabinoids}

Eleftherios G. Andriotis ${ }^{1}{ }^{*}$, Konstantina Chachlioutaki ${ }^{1}$, Paraskevi Kyriaki Monou ${ }^{1}$, Nikolaos Bouropoulos ${ }^{2,3}$, Dimitrios Tzetzis ${ }^{4}$, Panagiotis Barmpalexis ${ }^{1}$, Ming-Wei Chang $^{5}$, Zeeshan Ahmad ${ }^{6}$, Dimitrios G. Fatouros ${ }^{1}$

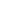
Sciences, Aristotle University of Thessaloniki, Thessaloniki GR-54124, Greece

${ }^{2}$ Department of Materials Science, University of Patras, 26504 Rio, Patras, Greece

${ }^{3}$ Foundation for Research and Technology Hellas, Institute of Chemical Engineering and High Temperature Chemical Processes, Patras, Greece

${ }^{4}$ School of Science and Technology, International Hellenic University, Thermi, GR57001, Greece

${ }^{5}$ Nanotechnology and Integrated Bioengineering Centre, University of Ulster, Jordanstown Campus, Newtownabbey BT37 0QB, Northern Ireland, UK

${ }^{6}$ Leicester School of Pharmacy, De Montfort University, LE1 9BH, Leicester, UK

${ }^{*}$ Corresponding author: Dr. Eleftherios G. Andriotis

e-mail: andrioti@auth.gr

Tel: +302310997653

Fax: +302310997652 
Abstract

Cannabidiol and cannabigerol are two active pharmaceutical ingredients, derived from cannabis plant. In the present study, CBD and CBG were co-formulated with polyvinyl(pyrrolidone) (PVP) and Eudragit L-100, using electrohydrodynamic atomization (electrospinning). The produced fibers were smooth and uniform in shape, with average fiber diameters in the range of $700-900 \mathbf{~ n m}$ for PVP fibers and 1- $5 \mu \mathrm{m}$ for Eudragit L-100 fibers. Drug loading and encapsulation efficiency were calculated for all formulations, with high encapsulation efficiencies (over $90 \%)$. Both in vitro release and in vitro disintegration tests of the formulations in SCF and SGF indicated the rapid dissolution of the fibers and the subsequent rapid release of the drugs. The study concluded that the electrospinning process is a fast and efficient method to produce drug-loaded fibers with enhanced properties, suitable for the per os administration of cannabinoids.

Keywords: cannabinoids, cannabidiol, cannabigerol, electrospinning, solid dispersion, nanofibers 


\section{Introduction}

Cannabis and plant-derived cannabinoids have received increasing attention for their potential use for medicinal purposes (1). More than one hundred phytocannabinoids have already been isolated and identified from Cannabis sativa (2). Phytocannabinoids are known to interact with the human body via the endocannabinoid system, by binding with $\mathrm{CB} 1$ or $\mathrm{CB} 2$ receptors, resulting in either an agonistic or antagonistic downstream effect $(3,4)$. Due to the wide distribution of these receptors, cannabinoids contribute significantly to human body processes $(5,6)$. One of the most important and most extensively studied cannabinoids, is $\Delta 9$-tetrahydrocannabinol ( $\triangle 9$-THC), mainly due to its psychoactive properties. However, non-psychoactive phytocannabinoids, such as cannabidiol (CBD) and (CBG) have received the attention of the scientific community, as they exhibit similar properties with $\triangle 9$-THC. CBD is the most promising of the nonpsychoactive cannabinoids due to its pharmacological actions and its abundance in hemp plants $(7,8)$. CBD has been studied for its potential anti-inflammatory activity, antitumoural and anti- angiogenic properties, anti-nausea action, and its ability to alleviate anxiety and pain (9-13). In addition to these, CBD has been asserted of playing a major role in the treatment of various medical conditions, such as multiple sclerosis, Parkinson's disease, Alzheimer's disease, epilepsy, rheumatoid arthritis, and diabetic complications (14-19). Food and Drug Agency (FDA) has already approved the use of CBD for the treatment of seizures associated with Lennox-Gastaut (LGS) or Dravet syndrome (DS) in pediatric patients, and marketed products based on highly purified CBD $\left(\right.$ Epidiolex $\left.^{\circledR}\right)$ are already being administered for the treatment of these diseases.

Another interesting phytochemical extracted from Cannabis sativa, CBG, plays one of the most significant roles in the biochemistry of the cannabis plant, as it is a chemical precursor to other cannabinoids. Recently, a growing amount of research in 
CBG's mechanism of action has revealed its polypharmacological profile, proving its potential health benefits (20). It is suggested that CBG interacts with the two G-proteincoupled receptors, $\mathrm{CB} 1$ and $\mathrm{CB} 2$, and it is claimed to increase the level of anandamide (the natural ligand of the endocannabinoid receptors), increasing in this way the levels of dopamine, and thus regulating functions such as sleep, mood, and appetite (21). One of the most promising beneficial effects of CBG use is its potential anti-inflammatory, antibacterial, and antidepressant properties $(22,23)$. Additionally, CBG is studied for glaucoma treatment as it contributes to the regulation and lowering of the intraocular pressure (20). Finally, CBG has a positive effect on inhibiting tumor growth in animal models of colorectal cancer (24).

Owing to their low oral bioavailability, efforts have been made towards the development of novel delivery systems via different routes of administration, such as transdermal, intranasal, and transmucosal $(25,26)$. Nevertheless, the oral route is the most common due to ease of administration. To this context, a wide range of formulations aimed for oral delivery has been reported including lipid-based delivery systems (SNEDDS), gastro retentive dosage forms, amorphous solid dispersions, and cyclodextrin inclusion complexes (27-31), focusing mainly to cannabinoids solubility enhancement effect.

In this direction, the concept of the development of solid dosage forms to deliver cannabinoids is a persistent challenge. The electrospinning process is considered as one of the most promising drug delivery platforms, aiming to overcome issues related to low dissolution rate (32). Electrospun-based drug delivery systems have flourished in several therapeutic fields due to their unique characteristics, such as flexible pore sizes, high surface area to volume ratio, and ease of production, resulting in ameliorating drug 
dissolution and subsequently to enhanced bioavailability of poorly water-soluble active pharmaceutical ingredients (APIs) (32).

The present study is focused on developing, for the first time, electrospun fibers loaded with CBD or CBG (used as model cannabinoids). Two different forms of electrospun fibers based on a nonionic hydrophilic polymer PVP and a $\mathrm{pH}$-responsive polymer (Eudragit-L100), loaded with CBG or CBD, were developed. PVP and Eudragit-L100 were selected as model excipients (matrix-carriers), due to their ability to improve the dissolution profiles when co-formulated with poorly water-soluble APIs, by forming amorphous solid dispersions (ASDs) $(33,34)$. The electrospinning process is one of the most efficient routes for the direct production of ASDs $(32,35,36)$, thus it was selected in this study for the co-formulation of model cannabinoids with two model excipients, towards the improvement of the solubility profiles of both CBD and CBG.

\section{Materials and Methods}

\section{Materials}

All reagents used were of standard analytical grade. CBD (crystals, $>99 \% \mathrm{CBD}, 1 \%$ terpenes by GC-MS, Enecta, Italy; provided by Hempoil ${ }^{\circledR}$, Athens, Greece) and CBG (crystals, > 99\% CBD, 1\% terpenes by GC-MS, Enecta, Italy; provided by Hempoil®, Athens, Greece) were used as received with no further purification. All cannabinoids were stored in amber vials purged with nitrogen to ensure an inert atmosphere. PVP (Povidone, average $\mathrm{Mw}=1,300,000$ by LS, Sigma-Aldrich, Darmstadt, Germany) and Eudragit L-100 (Poly(methacrylic acid-co-methyl methacrylate) 1:1, Rohm America, Darmstadt, Germany) were stored in a desiccator at room temperature to avoid any interaction with ambient humidity. All other materials and reagents were of analytical or pharmaceutical grade and were used as received. 


\section{Electrospinning Solution Preparation}

The electrospinning solutions were prepared according to literature $(35,37)$, with a slight modification. In a typical experiment, $10 \% \mathrm{w} / \mathrm{v}$ and $20 \% \mathrm{w} / \mathrm{v}$ electrospinning solutions were prepared by dissolving the respective polymer (PVP or Eudragit L-100) in ethanol, at room temperature, under magnetic stirring. A predetermined amount of the cannabinoids was added to the polymer solutions and the system was kept under magnetic stirring for at least $30 \mathrm{~min}$ before any further processing, to ensure complete dissolution. The different solution compositions are summarized in Table 1.

\section{Dynamic Viscosity Measurements}

The dynamic viscosity $(\mu)$ of the prepared solutions was measured based on previously reported studies (36). The dynamic viscosity of solutions of $10 \% \mathrm{w} / \mathrm{v}$ PVP and $20 \%$ w/v Eudragit L-100 in ethanol was measured using a rotational viscometer (Alpha series, Fungilab, Barcelona, Spain) at $25^{\circ} \mathrm{C}$.

\section{Conductivity Measurements}

The electrical conductivity of the polymer solutions was evaluated using a conductivity meter (Fisherbrand ${ }^{\mathrm{TM}}$ accumet $^{\mathrm{TM}}$ Basic AB30 Conductivity Meter, Fisher Scientific, Loughborough, UK). Briefly, $5 \mathrm{~mL}$ of each sample was incorporated in a glass tube and the measurement was started by immersing the electrode in the solution. The conductivity value was calculated by the average value of three independent measurements for each sample at ambient temperature.

\section{Electrospinning Process}

Electrospun fibers were prepared using an Electrospinning System (Starter Kit, E-Fiber electrospinning system, SKE Research Equipment ${ }^{\circledR}$, Bollate, Italy). The polymer/drug 
solutions were transferred in a $2 \mathrm{~mL}$ syringe, and the entrapped air was removed. The syringe was fitted with an 18-gauge needle and mounted onto the syringe pump apparatus. The feed rate was set to $1.0 \mathrm{~mL} / \mathrm{h}$ and $0.5 \mathrm{~mL} / \mathrm{h}$ for PVP and Eudragit-L100 solutions, respectively. The applied voltage was constant at $15 \pm 2 \mathrm{kV}$. The distance between the needle tip and the collector was set to $15 \mathrm{~cm}$. All process parameters were selected according to literature (35-38) and to a series of trial experiments. The process was carried out under ambient conditions. The fabricated fiber mats were collected and stored at a desiccator in dark, at room temperature.

\section{Scanning Electron Microscopy (SEM)}

The morphology of the electrospun samples was studied by a scanning electron microscope (Phenom ProX, ThermoFisher Scientific, Massachusetts, USA) in a high vacuum. Conductive double-sided carbon adhesive tape (TED Pella, Redding, California, USA) was used to mount the samples, which were subsequently coated by gold, using an ion sputtering device (Quorum SC7620, East Sussex, UK). A $15 \mathrm{kV}$ accelerating voltage was applied during the measurements. For fiber diameters distribution calculation, at least 100 measurements per sample were evaluated using the Phenom FiberMetric - Fiber Analysis Software.

\section{High-Performance Liquid Chromatography (HPLC)}

The quantification of $\mathrm{CBD}$ and $\mathrm{CBG}$ was performed by high-performance liquid chromatography (HPLC). The system consisted of a pump (LC-10 AD VP), an autosampler (SIL-20A HT), and an ultraviolet-visible detector (SPD-10A VP, Shimadzu, Kyoto, Japan). The chromatographic conditions were adapted from the literature, with modifications $(30,39)$. The stationary phase for CBD was a Discovery HS C18 $(15 \mathrm{~cm}$ 
$173 \times 4.6 \mathrm{~mm}, 3 \mu \mathrm{m})$ column and the mobile phase consisted of a mixture of (A) acetonitrile 174 and (B) phosphate buffer $\left(\mathrm{KH}_{2} \mathrm{PO}_{4}, 0.0126 \mathrm{M}, \mathrm{pH}\right.$ 5.0), A:B 80:20. The flow rate was 175 set at $1.0 \mathrm{~mL} / \mathrm{min}$ and the injection volume was $30 \mu \mathrm{L}$. The retention time of CBD and 176 CBG was 5.5 min and 5.0 min, respectively. Standard samples were tested in the range 177 of $0.5-100 \mu \mathrm{g} / \mathrm{mL}\left(\mathrm{R}^{2} \geq 0.9999\right)$. Typical chromatograms of CBD and CBG are given as supplementary data (Figure S1 \& S2).

179

\section{Drug Loading}

181 The drug loading and the entrapment efficiency of the samples were measured 182 according to the literature (38). Briefly, the prepared fibers were accurately weighed $183(10 \mathrm{mg})$ and dissolved in a mixture of acetonitrile:water 80:20 (1 mL). After complete dissolution, the drug loading and the entrapment efficiency were calculated employing HPLC analysis. The solution concentration was determined using a preconstructed calibration curve of the respective API. The results were presented as the average value of three independent measurements for each sample. CBD and CBG content, along with encapsulation efficiency was expressed according to the following equations:

$$
\text { Loading Capacity }(\%)=100 \times \mathrm{W}_{\text {drug }} / \mathrm{W}_{\text {drug loaded fiber }}
$$

where $\mathrm{W}_{\text {drug }}$ is the weight of the drug in fibrous film and $\mathrm{W}_{\text {drug loaded fiber }}$ is the weight of fibrous film sample.

$$
\text { Encapsulation Efficiency }(\%)=100 \times \mathrm{W}_{\text {drug }} / \mathrm{W}_{\text {drug used in the formulation }}
$$

where $\mathrm{W}_{\text {drug }}$ is the weight of the drug in fibrous film and $\mathrm{W}_{\text {drug used in the formulation }}$ is the initial weight of the drug used in the formulation. 

Spectroscopy

The ATR-FTIR spectra were recorded using a Shimadzu IR Prestige-21 spectrometer (Shimadzu, Kyoto, Japan) with a horizontal Golden-Gate MKII single reflection ATR system (Specac, Kent, UK) equipped with ZnSe lenses. In this study, each sample was scanned sixty-four times at $4 \mathrm{~cm}^{-1}$ resolution over the wavenumber range of 750 $4000 \mathrm{~cm}^{-1}$. The commercially available software IR Solutions (Shimadzu, Japan) was used to process the spectral data.

\section{Thermo-Gravimetric Analysis (TGA)}

The thermo-gravimetric analysis was performed by a TGA-50 thermogravimetric analyzer (Shimadzu, Tokyo, Japan). Briefly, 5mg of the samples were heated at a heating rate of $10^{\circ} \mathrm{C} / \mathrm{min}$ from room temperature to $900^{\circ} \mathrm{C}$ under nitrogen (flow rate of $50 \mathrm{~mL} / \mathrm{min}$ ). All experiments were performed in triplicate.

DSC analysis was performed by a differential scanning calorimeter 204 F1 Phoenix temperatures and enthalpies determined in this work were not higher than $1.0{ }^{\circ} \mathrm{C}$ and $3.0 \mathrm{~J} / \mathrm{g}$, respectively. The instrument was calibrated for temperature using high purity benzophenone, indium, and tin, while the enthalpic response was calibrated using indium. Thermograms were analyzed using the NETZSCH Proteus - Thermal Analysis 
software package version 5.2.1 (NETZSCH, Germany) and all experiments were conducted in triplicate.

\section{Powder X-ray Diffractometry (pXRD)}

The crystallinity of the samples was evaluated by XRD analysis, performed by an Xray diffractometer equipped with a LynxEye type detector (D8-Advance, Bruker, Karlsruhe, Germany). $\mathrm{Cu} \mathrm{K} \alpha$ radiation $(\lambda=0.154059 \mathrm{~nm})$ operated at $40 \mathrm{kV}$ and 40 $\mathrm{mA}$, was used. Data were collected over the $2 \theta$ range of $5^{\circ}-50^{\circ}$ at a scanning speed of $0.35 \mathrm{~s} / \mathrm{step}$ and step size of $0.02^{\circ}$.

\section{In vitro Release Studies}

The release of CBD and CBG was studied in Simulated Gastric Fluid (SGF; NaCl, 2 $\mathrm{g} / \mathrm{L} ; 1 \mathrm{M} \mathrm{HCl}, 80 \mathrm{~mL} / \mathrm{L} ; \mathrm{pH} 1.2)$ and in Simulated Intestinal Fluid (SIF; $\mathrm{KH}_{2} \mathrm{PO}_{4}, 6.805$ $\mathrm{g} / \mathrm{L} ; \mathrm{NaOH}, 0.896 \mathrm{~g} / \mathrm{L} ; \mathrm{pH}$ 6.8). Briefly, release studies for PVP fibers were conducted for $2 \mathrm{~h}$ in SGF and SIF, whereas releases studies containing Eudragit L-100 fibers were monitored over a $4 \mathrm{~h}$ period equally divided in SGF and SIF, to mimic the transition from gastric to intestinal conditions. All samples were fixed in metal-wire frames (30) to maintain a constant position into the release chamber and they were placed in doublewalled glass vessels filled with $40 \mathrm{~mL}$ of the release medium, enriched with $0.5 \%$ SLS, to ensure sink conditions (30). The experiments were conducted under constant stirring (100 rpm), at $37{ }^{\circ} \mathrm{C}$. Aliquots of $1 \mathrm{~mL}$ were withdrawn at specific time intervals, centrifuged at $4500 \mathrm{rcf}$ for $15 \mathrm{~min}$ and filtered through $0.45-\mu \mathrm{m}$ PVDF filters. The samples were analyzed in triplicate by HPLC to determine the concentration of CBD and CBG. Kinetic models were fitted to the release data to investigate the possible release mechanism of the APIs, using DDSolver software (40). The equations 3,4 and 
2475 describe the first order model, the Korsmeyer-Peppas model and the Peppas-Sahlin 248 model, respectively.

$$
\mathrm{dC} / \mathrm{dt}=\mathrm{K}(\mathrm{Cs}-\mathrm{C})
$$

250 where $\mathrm{C}$ is the concentration of the drug, $\mathrm{Cs}$ is the equilibrium solubility at the temperature of the process, $\mathrm{K}$ is the first order release constant and $\mathrm{t}$ is the time.

$$
\mathrm{Mt} / \mathrm{M}=\mathrm{Kt}^{\mathrm{n}}
$$

where $\mathrm{Mt}$ is the amount of drug released over time t, $\mathrm{M}$ is the amount of drug at the equilibrium state, $\mathrm{K}$ is the constant and $\mathrm{n}$ is the exponent of release and it is related to the release mechanism.

$$
\mathrm{Mt} / \mathrm{M}=\mathrm{K}_{1} \mathrm{t}^{\mathrm{m}}+\mathrm{K}_{2} \mathrm{t}^{2 \mathrm{~m}}
$$

where $\mathrm{K}_{1}$ and $\mathrm{K}_{2}$ are constants and $\mathrm{m}$ is the Fickian diffusion exponent for a system of any geometrical shape.

\section{In vitro Disintegration Test}

The in vitro disintegration time was determined according to a Petri dish method, with a slight modification $(41,42)$. A total volume of $2 \mathrm{~mL}$ SIF ( $\mathrm{pH}$ 6.8) or SGF (pH 1.2) was used for the disintegration test. Briefly, the prepared fibrous mats were placed in a glass petri dish and covered with the respective disintegration medium. Time-lapse videos (60 fps) of the procedure were recorded by a digital camera. The test was completed when the fibrous film was disintegrated. The recorded videos were converted to frames and the in vitro disintegration time was determined as the time needed for the complete disintegration of the sample.

\section{Water Uptake}


To evaluate the water uptake of Eudragit L-100 fiber mats, precisely weighed samples were placed in stainless steel mesh and immersed in two different media, SGF (pH 1.2) and SIF ( $\mathrm{pH}$ 6.8), respectively. The water uptake of the fibers was monitored for a period of $2 \mathrm{~h}$. At predetermined times intervals, the samples were removed from the apparatus, gently blotted with filter paper to remove excess water, and weighed. The percentage of water uptake was calculated from the following equation:

$$
\text { Water uptake }(\%)=\left(\mathrm{W}_{2}-\mathrm{W}_{1}\right) / \mathrm{W}_{1} \times 100
$$

where $\mathrm{W}_{2}$ is the weight of the wetted fibers and $\mathrm{W}_{1}$ is the initial weight of the fibers.

\section{Statistical Analysis}

Data were analyzed using Student's t-test. The significance level was set at $\mathrm{p}<0.05$.

\section{Results}

\section{Physical Properties of the Spinning Solutions}

Viscosity and conductivity measurements were performed for the spinning solutions containing PVP and Eudragit L-100 accordingly. The solution containing 10\% w/v PVP had a viscosity of $0.536 \pm 0.045 \mathrm{~Pa} \cdot \mathrm{s}$, while the viscosity of $20 \% \mathrm{w} / \mathrm{v}$ Eudragit L-100 solution was $0.758 \pm 0.1 \mathrm{~Pa} \cdot \mathrm{s}$ (Table 2). The conductivity of PVP and Eudragit L-100 solutions were also measured, and the results are depicted in Table 2.

\section{Electrospun Fibers Morphology}

Figure 1 shows the SEM images of the obtained fibers and the respective histograms of fibers' diameters distribution for CBD and CBG loaded nanofibers. The morphology analysis indicates that the applied electrospinning parameters resulted in the production of smooth and uniform fibers. PVP fibers have been successfully produced in 
cylindrical form while Eudragit L-100 fibers were characterized as flattened (ribbon-

297 like shape). Moreover, the addition of the drugs showed negligible differences with 298 plain solutions.

\section{Analysis of CBD and CBG Content}

301

302

303

The loading capacity and encapsulation efficiency of all the formulations were calculated as described above. Table 3 lists the values of all the produced fibers containing CBD and CBG. The encapsulation efficiency of both drugs is over $90 \%$ and the loading capacity is following the theoretical amount that was initially added in the solution.

\section{ATR-FTIR Spectroscopy}

The ATR-FTIR spectra of PVP and Eudragit L-100 fibers are shown in Figure 2. The spectrum of Eudragit L-100 reveals bands at $3258 \mathrm{~cm}^{-1}(-\mathrm{OH})$, at $2997 \mathrm{~cm}^{-1}\left(-\mathrm{OCH}_{3}\right)$, $2952 \mathrm{~cm}^{-1}\left(-\mathrm{CH}_{3}\right)$, and $1731 \mathrm{~cm}^{-1}(-\mathrm{C}=\mathrm{O})$. The spectrum of PVP reveals bands at 3468 $\mathrm{cm}^{-1}(-\mathrm{OH})$, at $2955 \mathrm{~cm}^{-1}\left(\mathrm{CH}_{2}\right)$, at $2876 \mathrm{~cm}^{-1}(\mathrm{C}-\mathrm{H})$, at $1657 \mathrm{~cm}^{-1}(\mathrm{C}=\mathrm{O})$, at $1422 \mathrm{~cm}^{-}$ ${ }^{1}(\mathrm{C}-\mathrm{H})$, and at $1279 \mathrm{~cm}^{-1}$ (C-N) (43). The ATR-FTIR spectra of PVP and Eudragit L100 fibers indicate the existence of relevant functional groups of PVP and Eudragit L100. In Figure 2, spectra of pure CBD and CBG are presented, showing two distinct peaks at $1618 \mathrm{~cm}^{-1}$ and $1577 \mathrm{~cm}^{-1}$, which are assigned to $\mathrm{C}=\mathrm{C}$ stretch vibration existing in both CBD and CBG (30). These characteristic peaks of the CBD and CBG are not detected in the ATR-FTIR spectra of the fibers. Additionally, the characteristic peaks of CBD and CBG are also not present in the spectra of physical mixture. 


\section{TGA Studies}

The thermal analysis of the fibers is presented in Figure 3. TGA was applied to investigate the thermal decomposition of fibers. As shown in Figure 3 (A) the thermal degradation of pure $\mathrm{CBD}$ and $\mathrm{CBG}$ was completed around $250^{\circ} \mathrm{C}$, close to its boiling point, whereas PVP and Eudragit L-100 decompose at a higher temperature $\left(450{ }^{\circ} \mathrm{C}\right)$. Figure 3 (B), (C) presents the recorded TGA thermograms of CBD-loaded fibers, two significant mass losses can be observed from room temperature to $100^{\circ} \mathrm{C}$ and from $200{ }^{\circ} \mathrm{C}$ until $300^{\circ} \mathrm{C}$, for drug-loaded fibers. The first mass loss, occurring from $70{ }^{\circ} \mathrm{C}$ to $100^{\circ} \mathrm{C}$ is attributed to water loss. The second mass loss of fibers, starting at $200^{\circ} \mathrm{C}$ is due to thermal degradation of the polymer matrix and drug. Similarly, the thermal stability of CBG-loaded fibers shows a similar pattern (Figure 3 (D), (E)). Specifically, fibers revealed a weight loss around $100^{\circ} \mathrm{C}$, corresponding to moisture evaporation. The second event occurring at around $250^{\circ} \mathrm{C}$ is characteristic of the thermal degradation of the CBG.

\section{DSC studies}

The DSC thermograms are presented in Figure 4. In regards to the pure APIs the characteristic sharp endothermic peaks for both $\mathrm{CBD}$ and $\mathrm{CBG}$, located at $68^{\circ} \mathrm{C}$ and $52^{\circ} \mathrm{C}$, respectively, are attributed to the melting point of the two drugs (44). Additionally, the DSC curves of the drug-loaded fibers exhibited only a wide endotherm around $100{ }^{\circ} \mathrm{C}$, corresponding to moisture evaporation, with no signs of APIs' melting, indicating that both drugs are probably amorphously dispersed within the prepared fibers matrices. In the case of Eudragit-L100, this hypothesis is verified by the DSC thermograms of the corresponding physical mixtures (Figure 4 (B), (D)), where the melting endotherms of the crystalline APIs are clearly depicted. The absence 
of the API endothermic peaks in the case of PVP physical mixtures (Figure 4 (A), (C)) may be attributed to drugs' DSC in-situ amorphization. Hence, to verify the amorphization of both drugs within the tested fiber mats, the physical state of both components was also evaluated via pXRD analysis.

\section{pXRD Analysis}

Figure 5 shows the pXRD patterns of the analyzed samples. As shown in Figure 5 (A) and (B), pure CBD is crystalline with a characteristic peak at $2 \theta=9.8,17.3$, and $21.4^{\circ}$. Additionally, characteristic peaks of pure CBG are visible in Figure 5 (C) and (D) at 15.2, 20.8, and 23.9 . Nevertheless, regarding drug-loaded PVP fibers and drug-loaded Eudragit-L100 fibers, no signs of the peaks were observed justifying the amorphous state of the drugs encapsulated into the fibers.

\section{In vitro Release Studies}

The in vitro release profile of all the formulations is presented in Figures 6 and 7. PVP fibers dissolve within $1 \mathrm{~h}$ in both SGF and SIF media, whereas Eudragit-L100 fibers dissolve only in SIF within 2 h. In detail, Figure 6 (A) and 6 (B) depicts the release of CBD from the PVP fibers in SGF and SIF respectively. Complete dissolution of the fibers in the SGF medium, within the first 20 to $30 \mathrm{~min}$, results in a $100 \%$ release of CBD, while 2PVP release the drug within 40 min. 1PVP and 2PVP release the drug within 30 min while 3PVP reaches the $100 \%$ release within $40 \mathrm{~min}$. In regards, to drug release kinetics, the release profile of 1PVP and 3PVP in SGF medium and 1PVP and 2PVP in SIF medium follow the Korsmeyer-Peppas model $\left(\mathrm{R}^{2}=0.9673\right.$ and 0.9916 , respectively; $\mathrm{n}<0.5$ ) whereas the release data from 2PVP in SGF medium and 3PVP in SIF medium follow a first-order model $\left(\mathrm{R}^{2}=0.9947,0.9776\right.$, respectively). 
Figure 6 (C) depicts the release behavior of CBD from the Eudragit fibers. As evident, CBD release is up to $10 \%$ in SGF and as the fibers dissolve in SIF, CBD is completely released. Release kinetics showed that 7EUDR, 8EUDR, and 9EUDR fibers in the SIF medium follow the Peppas-Sahlin model $\left(\mathrm{R}^{2}=0.9674,0.9272,0.9674\right.$, respectively; $\mathrm{m}$ $<0.5)$.

Figure 7 presents the release profile of CBG. All formulations have a rapid release within $30 \mathrm{~min}$, while 6PVP releases the drug in a more controlled way. CBG was released from PVP fibers in SIF (Figure 7 (B)), within 20 min. The Korsmeyer-Peppas model was fitted to 4PVP and 5PVP fibers $\left(\mathrm{R}^{2}=0.9874,0.9272\right.$, respectively, $\left.\mathrm{n}<0.5\right)$, and the Peppas-Sahlin model was fitted to 6PVP formulation $\left(\mathrm{R}^{2}=0.9593, \mathrm{~m}<0.5\right)$. All the release data from SIF were fitted to the first-order model $\left(\mathrm{R}^{2}=0.9654-0.9766\right)$. Eudragit fibers release up to $12 \%$ of CBG in SGF and complete dissolution of the fibers in SIF release $100 \%$ of the API within $2 \mathrm{~h}$. The release data from SIF were fitted to the first-order model $\left(\mathrm{R}^{2}=0.9123-0.9772\right)$.

\section{Disintegration Test}

The disintegration test and wettability studies were carried out by placing $2 \mathrm{~cm}$ diameter circular samples of the fibers in SGF and SIF, recording the whole process using a digital camera. The results were presented in Figure 8. Specifically, a complete disintegration of the PVP fibrous structure was occurred in less than $20 \mathrm{sec}$ as evident from Figure 8 (A) \& (B). On the contrary Eudragit L-100 fibers showed the expected resistance to dissolution in acidic medium (SGF), whereas they appeared to lose their structure in a moderate rate at neutral $\mathrm{pH}$ medium (SIF), resulting in a slow disintegration of the fibers (Figure $8(\mathrm{C}),(\mathrm{D})$ ). 


\section{Water Uptake}

To evaluate the hydration capacity of drug-loaded Eudragit-L100 fibers, swelling studies were performed (Figure 9). The water uptake of Eudragit-L100 fibers in SIF was almost constant for $30 \mathrm{~min}$; then, the samples started to gradually dissolve with an increasing rate.

\section{Discussion}

The objective of this study was to investigate the incorporation of cannabinoids into a polymer matrix via the electrospinning process. $\mathrm{CBD}$ and $\mathrm{CBG}$ loaded fibers were successfully formed by electrospinning technique utilizing PVP and Eudragit L-100 as model matrix carriers.

The SEM images of the produced fibers showed that the prepared solutions resulted in uniform and smooth fibers with a satisfying average diameter. The morphology of the fibers and the absence of beaded fibers, with non-uniform regions is consistent with previous reported studies where electrospun fibers comprised of PVP and Eudragit L100 (35,37). The formation of ribbon-like shape fibers containing Eudragit L-100 fibers has been previously reported for fibers with diameters in the range of 1-2 $\mu \mathrm{m}$ (45).

The amount of the cannabinoids within the electrospun fibers, was quantified by HPLC analysis. The results are presented in terms of the percentage of loading capacity and encapsulation efficiency of CBD, CBG (Table 3). The high encapsulation efficiency $(>90 \%)$ is attributed to the electrospinning process, due to rapid solvent evaporation and fast fiber formation (32).

The fabricated fibers along with the pristine materials and their physical mixtures, were analyzed by ATR-FTIR, to investigate the presence of any possible change of the chemical structure of the system during the electrospinning process. The absence of the 
characteristic peaks of the two cannabinoids from both the fibers and the physical mixtures, is a strong indication that the amount of API within the samples is below the detection limit of the instrument, and thus the deduction of any conclusion regarding the amorphization of the API is not safe.

To further investigate the thermophysical properties of the electrospun fibers, TGA analysis was performed. The thermograms are indicative of the hydroscopic nature of both polymers, as there is a mass loss that is attributed to moisture evaporation from the fibers. On the other hand, the mass loss that is observed for all the samples due to APIs' phase change close to their respective boiling points, is an indication that there the thermal properties of the cannabinoids $\left(\mathrm{T}_{\mathrm{m}}\right)$ have not been altered.

The thermophysical properties of the system were further studied by means of DSC analysis. The DSC thermograms of the pure APIs, illustrated the characteristic endothermic peaks of $\mathrm{CBD}$ and $\mathrm{CBG}$ at $62^{\circ} \mathrm{C}$ and $58^{\circ} \mathrm{C}$, respectively, attributed to their melting point $(30,31,44)$. The absence of these peaks in the drug-loaded fibers implies that the APIs could be in amorphous state (34).

To verify the amorphous state of the selected cannabinoids, the pXRD studies were performed to the formatted fibers. pXRD patterns of pure drugs showed characteristic peaks of their crystalline structure (29). On the other hand, the diffractograms of PVP and Eudragit L-100 fibers reveal broad halos typical for amorphous materials (46). The absence of the characteristic peaks of the CBD and CBG from the diffractograms is attributed to the amorphous state of the two substances within the electrospun fibers. The release profiles of the two model cannabinoids from the prepared electrospun fibers were studied in vitro. The studies indicated a burst release of CBD and CBG from PVP fibers in SGF and SIF media, whereas both APIs were released from Eudragit L-100 fibers in a $\mathrm{pH}$-controlled manner, exhibiting negligible release in lower $\mathrm{pH}$ values (SGF 
medium) and a burst release in the simulated intestinal environment (SIF medium). These observations are consistent with similar systems previously described in the literature $(35,46,47)$, as PVP fibers are readily dissolvable in aqueous media (both SGF and SIF), while Eudragit L-100 fibers are not dissolvable in acidic environment. The release data obtained for the samples 1PVP and 3PVP in SGF and 1PVP and 2PVP in SIF were best fitted to the Korsmeyer-Peppas kinetic model, and based on the ' $n$ ' values, it was concluded that the release is governed by Fickian diffusion $(n<0.5)(48-50)$. On the other hand, CBD is released from 2PVP in SGF and 3PVP in SIF medium following the first-order model, indicating that CBD is released in a constant rate between the amount of the drug remaining in the polymer matrix and the released drug (51). In either case, the release of CBD from PVP fibers is mainly affected by the fast dissolution rate of the polymeric fiber, due to the highly hydrophilic nature of PVP (52).

The release profiles of CBD from Eudragit L-100 fibers were studied in SIF medium, as the fibers were not dissolved in acidic environment. The release data obtained for the samples 7EUDR, 8EUDR, and 9EUDR in SIF were fitted to the Peppas-Sahlin model $\left(\mathrm{R}^{2}=0.9674,0.9272,0.9674\right.$, respectively; $\left.\mathrm{m}<0.5\right)$, indicating that the release of the API is owed to diffusion and relaxation of the polymeric chains (53), attributed to the time-dependent swelling of the polymer, in SIF medium $(35,46)$.

The in vitro release studies of CBG-containing electrosun fibers, were in close agreement with those obtained for CBD. All formulations exhibited a rapid release within $30 \mathrm{~min}$, with the exception of 6PVP where drug release was slower. The Korsmeyer-Peppas model was fitted to samples 4PVP and 5PVP $\left(\mathrm{R}^{2}=0.9874,0.9272\right.$, respectively, $\mathrm{n}<0.5)$, and the Peppas-Sahlin model was best-fitted to sample 6PVP $\left(\mathrm{R}^{2}\right.$ $=0.9593, \mathrm{~m}<0.5)$. All the release data obtained for SIF medium, were fitted to the first-order model $\left(\mathrm{R}^{2}=0.9654-0.9766\right)$. In a similar way to CBD release from drug- 
loaded PVP fibers, the phenomenon is governed mainly by the fast dissolution of the polymer (as it is described by the Korsmeyer-Peppas model), with the exception of the sample 6PVP, where the swelling of the polymer seems to play a minor role, indicating the presence of drug-polymer interaction of a low extent.

Eudragit fibers released up to $12 \%$ of CBG in SGF and complete dissolution of the fibers in SIF release $100 \%$ of the API within $2 \mathrm{~h}$. The release data from SIF were fitted to the first-order model $\left(\mathrm{R}^{2}=0.9123-0.9772\right)$, indicating the fast dissolution rate of the polymer in SIF medium.

To visualize the fast dissolution rates of both polymers in the studied media, the in vitro disintegration test was applied to the electrospun fibers (42). Drug-loaded PVP fibers were completely wetted and disintegrated in both simulated fluids (SGF, SIF) losing their original shape within $20 \mathrm{~s}$, as illustrated in Figure 8 (A) and (B). This rapid disintegration of drug-loaded PVP fibers in both simulated fluids might be attributed to the highly porous structure of the produced fibers during the electrospinning process (55). The porosity of fibers is related to their ability to absorb large quantities of water causing their disintegration in a few seconds. Hence, it can be deduced that the rapid disintegration of fiber structure allowed at the same time the fast release of the drug from the polymer matrix (47).

The disintegration time of drug-loaded Eudragit L-100 fiber mats could not be precisely determined due to the controlled dissolution of the polymer matrix. Hence, the results obtained from the time-lapsed videos (Figure 8 (C), (D)) show a wetting behavior of the fiber mats in SIF until $300 \mathrm{sec}$ with a time-dependent erosion in the polymer matrix. On the contrary, drug-loaded Eudragit fibers are insoluble in acidic $\mathrm{pH}$ (SGF $\mathrm{pH}$ 1.2) as shown in Figure $8(\mathrm{C}),(\mathrm{D})$. To this context, the rate and the extent of Eudragit L100 fibers hydration were investigated at an acidic medium (SGF) and a neutral $\mathrm{pH}$ 
medium (SIF), to monitor and mimic the transition from gastric to intestinal environment (30). The maximum water uptake was achieved within the first $20 \mathrm{~min}$ in both simulated fluids with the the polymer matrix preserving its structure in the acidic medium, whereas a complete disintegration of the fiber structure was observed in SIF medium at the timescale of $2 \mathrm{~h}$ in $\mathrm{pH}=6.8$.

\section{Conclusions}

To our best knowledge this the first report where electrospinning process was successfully applied to produce submicron fibers containing the model cannabinoids CBD and CBG accordingly. The incorporation of the two poorly water-soluble APIs in two different model excipients (PVP and Eudragit L-100) has led to the increase of CBD's and CBG's solubility, rendering this manufacturing approach suitable for the preparation of water-soluble formulations for per os administration of cannabinoids.

\section{References}

1. Deiana S, Watanabe A, Yamasaki Y, Amada N, Arthur M, Fleming S, et al. Plasma and brain pharmacokinetic profile of cannabidiol (CBD), cannabidivarine (CBDV), $\triangle 9$-tetrahydrocannabivarin (THCV) and cannabigerol (CBG) in rats and mice following oral and intraperitoneal administration and CBD action on obsessive-compulsive behaviour. Psychopharmacology. 2012 Feb;219(3):85973.

2. ElSohly MA, Slade D. Chemical constituents of marijuana: The complex mixture of natural cannabinoids. Life Sciences. 2005 Dec;78(5):539-48.

3. Pacher P, Bátkai S, Kunos G. The Endocannabinoid System as an Emerging Target of Pharmacotherapy. Pharmacol Rev. 2006 Sep;58(3):389-462. 
4. Wassmann CS, Højrup P, Klitgaard JK. Cannabidiol is an effective helper compound in combination with bacitracin to kill Gram-positive bacteria. Sci Rep. 2020 Dec;10(1):4112.

5. Kraft B. Is There Any Clinically Relevant Cannabinoid-Induced Analgesia. Pharmacology. 2012;89(5-6):237-46.

6. Guindon J, Hohmann AG. The endocannabinoid system and pain. CNS Neurol Disord Drug Targets. 2009 Dec;8(6):403-21.

7. Premoli M, Aria F, Bonini SA, Maccarinelli G, Gianoncelli A, Pina SD, et al. Cannabidiol: Recent advances and new insights for neuropsychiatric disorders treatment. Life Sciences. 2019 May;224:120-7.

8. Zuardi AW. Cannabidiol: from an inactive cannabinoid to a drug with wide spectrum of action. Rev Bras Psiquiatr. 2008 Sep;30(3):271-80.

9. Pisanti S, Malfitano AM, Ciaglia E, Lamberti A, Ranieri R, Cuomo G, et al. Cannabidiol: State of the art and new challenges for therapeutic applications. Pharmacology \& Therapeutics. 2017 Jul;175:133-50.

10. Romano B, Borrelli F, Pagano E, Cascio MG, Pertwee RG, Izzo AA. Inhibition of colon carcinogenesis by a standardized Cannabis sativa extract with high content of cannabidiol. Phytomedicine. 2014 Apr;21(5):631-9.

11. Parker LA, Mechoulam R, Schlievert C. Cannabidiol, a non-psychoactive component of cannabis and its synthetic dimethylheptyl homolog suppress nausea in an experimental model with rats: Neuroreport. 2002 Apr;13(5):567-70.

12. Boychuk DG, Goddard G, Mauro G, Orellana MF. The Effectiveness of Cannabinoids in the Management of Chronic Nonmalignant Neuropathic Pain: A Systematic Review. J Oral Facial Pain Headache. 2015 Jan;29(1):7-14. 
13. Solinas M, Massi P, Cantelmo A, Cattaneo M, Cammarota R, Bartolini D, et al. Cannabidiol inhibits angiogenesis by multiple mechanisms: Cannabidiol and angiogenesis. British Journal of Pharmacology. 2012 Nov;167(6):1218-31.

14. Rudroff T, Sosnoff J. Cannabidiol to Improve Mobility in People with Multiple Sclerosis. Frontiers in Neurology. 2018;9:183.

15. More SV, Choi D-K. Promising cannabinoid-based therapies for Parkinson's disease: motor symptoms to neuroprotection. Mol Neurodegener. 2015 Apr $8 ; 10: 17$.

16. Aso E, Ferrer I. Cannabinoids for treatment of Alzheimer's disease: moving toward the clinic. Front Pharmacol [Internet]. 2014 Mar 5 [cited 2020 Oct 1];5

17. Silvestro S, Mammana S, Cavalli E, Bramanti P, Mazzon E. Use of Cannabidiol in the Treatment of Epilepsy: Efficacy and Security in Clinical Trials. Molecules. 2019 Apr 12;24(8):1459.

18. Malfait AM, Gallily R, Sumariwalla PF, Malik AS, Andreakos E, Mechoulam R, et al. The nonpsychoactive cannabis constituent cannabidiol is an oral antiarthritic therapeutic in murine collagen-induced arthritis. Proceedings of the National Academy of Sciences. 2000 Aug 15;97(17):9561-6.

19. Noreen N, Muhammad F, Akhtar B, Azam F, Anwar MI. Is Cannabidiol a Promising Substance for New Drug Development? A Review of its Potential Therapeutic Applications. Crit Rev Eukaryot Gene Expr. 2018;28(1):73-86.

20. Deiana S. Potential Medical Uses of Cannabigerol: A Brief Overview. In: Handbook of Cannabis and Related Pathologies [Internet]. Elsevier; 2017 [cited 2020 Oct 1]. p. 958-67. 
21. Brierley DI, Samuels J, Duncan M, Whalley BJ, Williams CM. Cannabigerol is a novel, well-tolerated appetite stimulant in pre-satiated rats. Psychopharmacology. 2016 Oct;233(19-20):3603-13.

22. Borrelli F, Fasolino I, Romano B, Capasso R, Maiello F, Coppola D, et al. Beneficial effect of the non-psychotropic plant cannabinoid cannabigerol on experimental inflammatory bowel disease. Biochemical Pharmacology. 2013 May;85(9):1306-16.

23. Appendino G, Gibbons S, Giana A, Pagani A, Grassi G, Stavri M, et al. Antibacterial Cannabinoids from Cannabis sativa: A Structure-Activity Study. J Nat Prod. 2008 Aug;71(8):1427-30.

24. Borrelli F, Pagano E, Romano B, Panzera S, Maiello F, Coppola D, et al. Colon carcinogenesis is inhibited by the TRPM8 antagonist cannabigerol, a Cannabisderived non-psychotropic cannabinoid. Carcinogenesis. 2014 Dec;35(12):278797.

25. Paudel KS, Hammell DC, Agu RU, Valiveti S, Stinchcomb AL. Cannabidiol bioavailability after nasal and transdermal application: effect of permeation enhancers. Drug Development and Industrial Pharmacy. 2010 Sep 1;36(9):108897.

26. Itin C, Barasch D, Domb AJ, Hoffman A. Prolonged oral transmucosal delivery of highly lipophilic drug cannabidiol. International Journal of Pharmaceutics. 2020 May;581:119276.

27. Izgelov D, Shmoeli E, Domb AJ, Hoffman A. The effect of medium chain and long chain triglycerides incorporated in self-nano emulsifying drug delivery systems on oral absorption of cannabinoids in rats. International Journal of Pharmaceutics. 2020 Apr;580:119201. 
28. Izgelov D, Freidman M, Hoffman A. Investigation of cannabidiol gastro retentive tablets based on regional absorption of cannabinoids in rats. European Journal of Pharmaceutics and Biopharmaceutics. 2020 Jul;152:229-35.

29. Lv P, Zhang D, Guo M, Liu J, Chen X, Guo R, et al. Structural analysis and cytotoxicity of host-guest inclusion complexes of cannabidiol with three native cyclodextrins. Journal of Drug Delivery Science and Technology. 2019 Jun;51:337-44.

30. Andriotis EG, Monou P-K, Louka A, Papaefstathiou E, Eleftheriadis GK, Fatouros DG. Development of food grade 3D printable ink based on pectin containing cannabidiol/cyclodextrin inclusion complexes. Drug Development and Industrial Pharmacy. 2020;1-9.

31. Koch N, Jennotte O, Gasparrini Y, Vandenbroucke F, Lechanteur A, Evrard B. Cannabidiol aqueous solubility enhancement: Comparison of three amorphous formulations strategies using different type of polymers. International Journal of Pharmaceutics. 2020 Nov;589:119812.

32. Yu D-G, Li J-J, Williams GR, Zhao M. Electrospun amorphous solid dispersions of poorly water-soluble drugs: A review. Journal of Controlled Release. 2018 Dec;292:91-110.

33. Monschke M, Wagner KG. Amorphous solid dispersions of weak bases with pHdependent soluble polymers to overcome limited bioavailability due to gastric $\mathrm{pH}$ variability - An in-vitro approach. International Journal of Pharmaceutics. 2019 Jun;564:162-70.

34. Kapourani A, Chatzitheodoridou M, Kontogiannopoulos KN, Barmpalexis P. Experimental, Thermodynamic, and Molecular Modeling Evaluation of 

Pharmaceutics. 2020 Jul 6;17(7):2703-20.

618

619

620

621

622

623

35. Reda R, Wen MM, El-Kamel A. Ketoprofen-loaded Eudragit electrospun nanofibers for the treatment of oral mucositis. IJN. 2017 Mar;Volume 12:233551.

36. Ignatova M, Manolova N, Rashkov I. Novel antibacterial fibers of quaternized chitosan and poly(vinyl pyrrolidone) prepared by electrospinning. European Polymer Journal. 2007 Apr;43(4):1112-22.

37. Chuangchote S, Sagawa T, Yoshikawa S. Electrospinning of poly(vinyl pyrrolidone): Effects of solvents on electrospinnability for the fabrication of poly(p-phenylene vinylene) and TiO2 nanofibers. J Appl Polym Sci. 2009 Dec 1;114(5):2777-91.

38. Nazari K, Kontogiannidou E, Haj Ahmad R, Andreadis D, Rasekh M, Bouropoulos N, et al. Fibrous polymeric buccal film formulation, engineering and bio-interface assessment. European Polymer Journal. 2017 Dec;97:147-57.

39. Brighenti V, Pellati F, Steinbach M, Maran D, Benvenuti S. Development of a new extraction technique and HPLC method for the analysis of non-psychoactive cannabinoids in fibre-type Cannabis sativa L. (hemp). Journal of Pharmaceutical and Biomedical Analysis. 2017 Sep;143:228-36.

40. Zhang Y, Huo M, Zhou J, Zou A, Li W, Yao C, et al. DDSolver: An Add-In Program for Modeling and Comparison of Drug Dissolution Profiles. AAPS J. 2010 Sep;12(3):263-71.

41. Garsuch V, Breitkreutz J. Comparative investigations on different polymers for the preparation of fast-dissolving oral films. Journal of Pharmacy and Pharmacology. 2010 Apr;62(4):539-45. 
42. Chachlioutaki K, Tzimtzimis EK, Tzetzis D, Chang M-W, Ahmad Z, Karavasili C, et al. Electrospun Orodispersible Films of Isoniazid for Pediatric Tuberculosis Treatment. Pharmaceutics. 2020 May 21;12(5):470.

43. Huang S, Zhou L, Li M-C, Wu Q, Kojima Y, Zhou D. Preparation and Properties of Electrospun Poly (Vinyl Pyrrolidone)/Cellulose Nanocrystal/Silver Nanoparticle Composite Fibers. Materials. 2016 Jun 28;9(7):523.

44. Stinchcomb AL, Valiveti S, Hammell DC, Ramsey DR. Human skin permeation of Delta8-tetrahydrocannabinol, cannabidiol and cannabinol. Journal of Pharmacy and Pharmacology. 2004 Mar;56(3):291-7.

45. Koombhongse S, Liu W, Reneker DH. Flat polymer ribbons and other shapes by electrospinning. J Polym Sci B Polym Phys. 2001 Nov 1;39(21):2598-606.

46. Illangakoon UE, Yu D-G, Ahmad BS, Chatterton NP, Williams GR. 5Fluorouracil loaded Eudragit fibers prepared by electrospinning. International Journal of Pharmaceutics. 2015 Nov;495(2):895-902.

47. Samprasit W, Akkaramongkolporn P, Ngawhirunpat T, Rojanarata T, Kaomongkolgit R, Opanasopit P. Fast releasing oral electrospun PVP/CD nanofiber mats of taste-masked meloxicam. International Journal of Pharmaceutics. 2015 Jun;487(1-2):213-22.

48. Barman M, Mahmood S, Augustine R, Hasan A, Thomas S, Ghosal K. Natural halloysite nanotubes /chitosan based bio-nanocomposite for delivering norfloxacin, an anti-microbial agent in sustained release manner. International Journal of Biological Macromolecules. 2020 Nov;162:1849-61.

49. Ghosal K, Adak S, Agatemor C, G P, Kalarikkal N, Thomas S. Novel interpenetrating polymeric network based microbeads for delivery of poorly water soluble drug. J Polym Res. 2020 Apr;27(4):98. 
50. Ghosal K, Das A, Das SK, Mahmood S, Ramadan MAM, Thomas S. Synthesis and characterization of interpenetrating polymeric networks based bio-composite alginate film: A well-designed drug delivery platform. International Journal of Biological Macromolecules. 2019 Jun;130:645-54.

51. Ammoury N, Fessi H, Devissaguet JP, Puisieux F, Benita S. In Vitro Release Kinetic Pattern of Indomethacin from Poly(D,L-Lactide) Nanocapsules. Journal of Pharmaceutical Sciences. 1990 Sep;79(9):763-7.

52. Wojcik-Pastuszka D, Krzak J, Macikowski B, Berkowski R, Osiński B, Musiał W. Evaluation of the Release Kinetics of a Pharmacologically Active Substance from Model Intra-Articular Implants Replacing the Cruciate Ligaments of the Knee. Materials. 2019 Apr 12;12(8):1202.

53. Mathematical models of drug release. In: Strategies to Modify the Drug Release from Pharmaceutical Systems [Internet]. Elsevier; 2015 [cited 2020 Oct 1]. p. 6386.

54. Illangakoon UE, Gill H, Shearman GC, Parhizkar M, Mahalingam S, Chatterton NP, et al. Fast dissolving paracetamol/caffeine nanofibers prepared by electrospinning. International Journal of Pharmaceutics. 2014 Dec;477(1-2):36979.

Table 1. Different compositions of the spinning solutions.

\begin{tabular}{lccc}
\hline Sample & $\begin{array}{c}\text { Polymer Concentration } \\
(\% \mathrm{w} / \mathrm{v})^{*}\end{array}$ & $\begin{array}{c}\text { Cannabinoid } \\
\text { Concentration }(\% \mathrm{w} / \mathrm{w})^{* *}\end{array}$ & $\begin{array}{c}\text { Type of } \\
\text { Cannabinoid }\end{array}$ \\
\hline 1PVP & & 0.5 & CBD \\
2PVP & 10 & 1 & \\
3PVP & & 1.5 & $\mathrm{CBG}$ \\
4PVP & & 0.5 & \\
5PVP & 1 & 1.5 & \\
6PVP & & & \\
\hline
\end{tabular}




\begin{tabular}{lccc}
\hline 7EUDR & 0.5 & \\
8 EUDR & & 1 & CBD \\
9 EUDR & 20 & 1.5 & \\
$10 \mathrm{EUDR}$ & & 0.5 & $\mathrm{CBG}$ \\
$11 \mathrm{EUDR}$ & 1 & \\
$12 \mathrm{EUDR}$ & 1.5 & \\
\hline
\end{tabular}

*Final polymer concentration in ethanol

**Concentration based on the final polymer content

685

686

687

688

689

690

691

692

693

694

695 Table 3. Loading capacity (\%) and Encapsulation efficiency (\%) of the formulations.

\begin{tabular}{ccc}
\hline Sample & Loading Capacity (\%) & Encapsulation efficiency (\%) \\
\hline 1PVP & 0.47 & 93.90 \\
2PVP & 0.99 & 99.00 \\
3PVP & 1.48 & 98.10 \\
4PVP & 0.49 & 98.56 \\
5PVP & 0.97 & 97.10 \\
6PVP & 1.46 & 97.13 \\
\hline
\end{tabular}




\begin{tabular}{lll}
\hline 7EUDR & 0.45 & 90.50 \\
8EUDR & 0.95 & 95.45 \\
9EUDR & 1.48 & 98.50 \\
$10 \mathrm{EUDR}$ & 0.49 & 98.88 \\
$11 \mathrm{EUDR}$ & 0.94 & 93.65 \\
$12 \mathrm{EUDR}$ & 1.42 & 94.35 \\
\hline
\end{tabular}

696

697

698

699

700

701

702

703

704

705

706

707

708

709

710

711

712

713

714

715

FIGURE LEGENDS

716

717 Figure 1. SEM images and average diameter distribution histograms of a. CBD loaded 718 PVP fibers (A) PVP, (B) 1PVP, (C) 2PVP, (D) 3PVP, b. CBD loaded Eudragit L-100 719 fibers I Eudragit L-100, (F) 7EUDR, (G) 8EUDR, (H)9EUDR, c. CBG loaded PVP 720 fiber mats (I)PVP, (J)4PVP, (K)5PVP, (L)6PVP, d. CBG loaded Eudragit L-100 fibers 721 (M) Eudragit L-100, (N)10EUDR, (0)11EUDR, (P)12EUDR. 
723

724

725

726

727

728

729

730

731

732

733

734

735

736

737

738

739

740

741

742

743

744

745

746

Figure 2. ATR-FTIR spectra of (A) as-spun PVP/CBD fibers and Physical mixtures, (B) as-spun Eudragit L-100/CBD fibers and Physical mixtures, (C) as-spun PVP/CBG fibers and Physical mixtures, (D) as-spun Eudragit L-100/CBG fibers and Physical mixtures.

Figure 3. TGA results of nanofibers: (A) Raw material, (B) as spun PVP/CBD fibers, (C) as spun Eudragit L-100/CBD fibers, (D) as spun PVP/CBG fibers, (E) as spun Eudragit L-100/CBG fibers.

Figure 4. DSC thermograms of nanofibers: (A) PVP/CBD fibers and Physical mixtures, (B) Eudragit L-100/CBD fibers and Physical mixtures, (C) PVP/CBG fibers and Physical mixtures, (D) Eudragit L-100/CBG fibers and physical mixtures.

Figure 5. pXRD pattern of (A) PVP/CBD fibers; (B) Eudragit L-100/CBD fibers, (C) PVP/CBG fibers, (D) Eudragit L-100/CBG fibers.

Figure 6. Release profile of CBD from PVP fibers in (A) SGF and (B) SIF and from Eudragit fibers (C) in SGF and SIF.

Figure 7. Release profile of CBG from PVP fibers in (A) SGF and (B) SIF and from Eudragit fibers (C) in SGF and SIF.

Figure 8. Disintegration test of fiber in Simulated fluids: (A) 3PVP in SGF and SIF, (B) 6PVP in SGF and SIF, (C) 9EUDR in SGF and SIF, (D) 12EUDR in SGF and SIF. 
Figure 9. Swelling plot of drug-loaded Eudragit L-100 fibers: (A) in SGF, (B) in SIF

748

749

750

751

752

753

754

755

756

757

758

759

760

761

762

763

764

765

766

767

768

769

770

771

772 FIGURE 1 
a
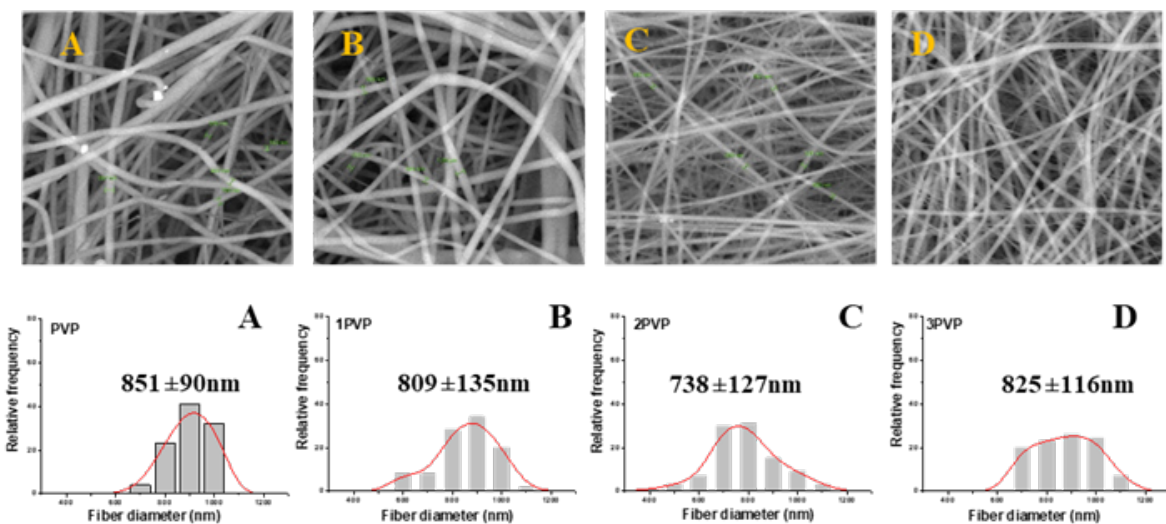

b
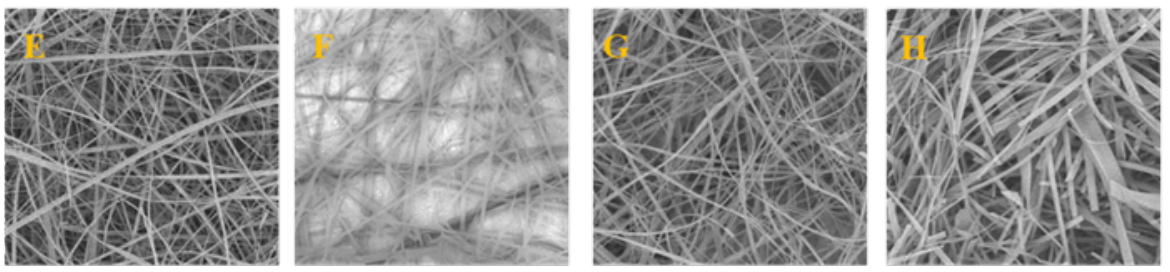

773
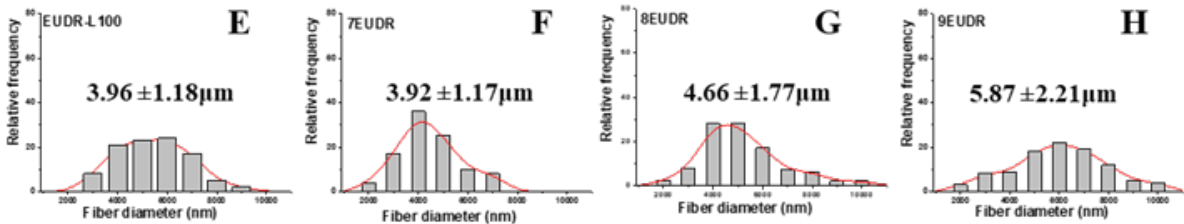

c
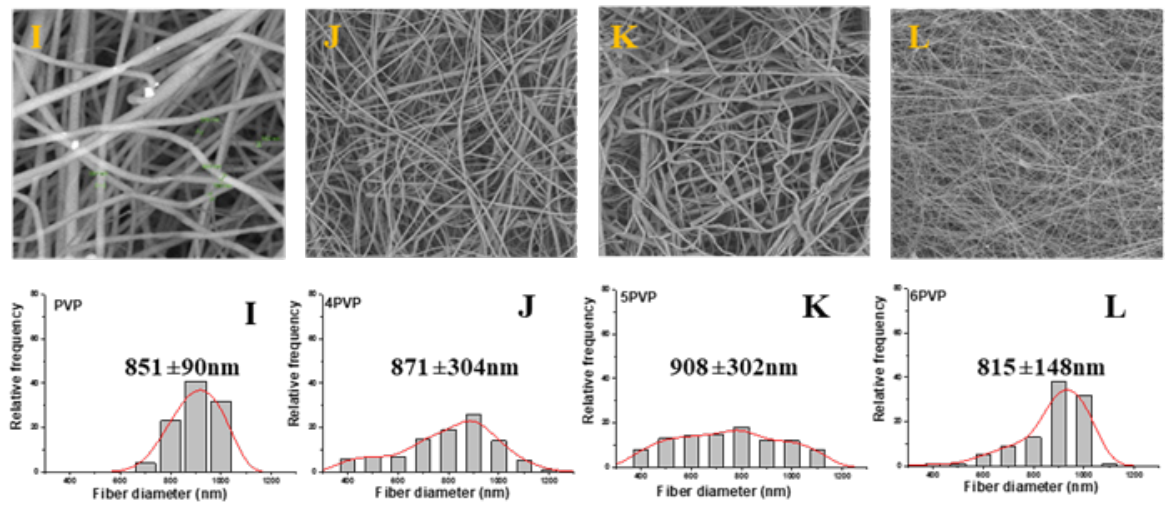

d
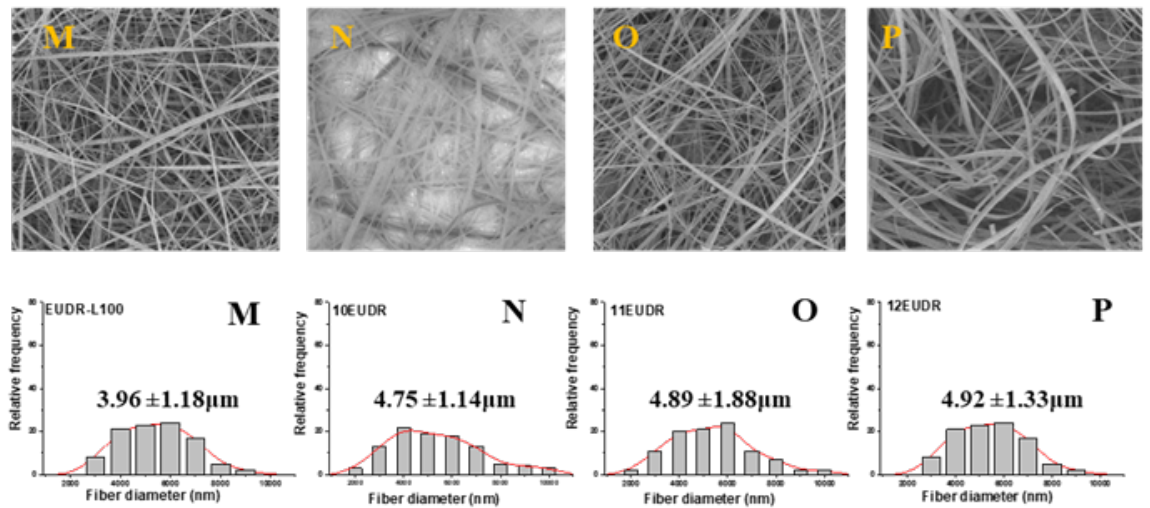

FIGURE 2 

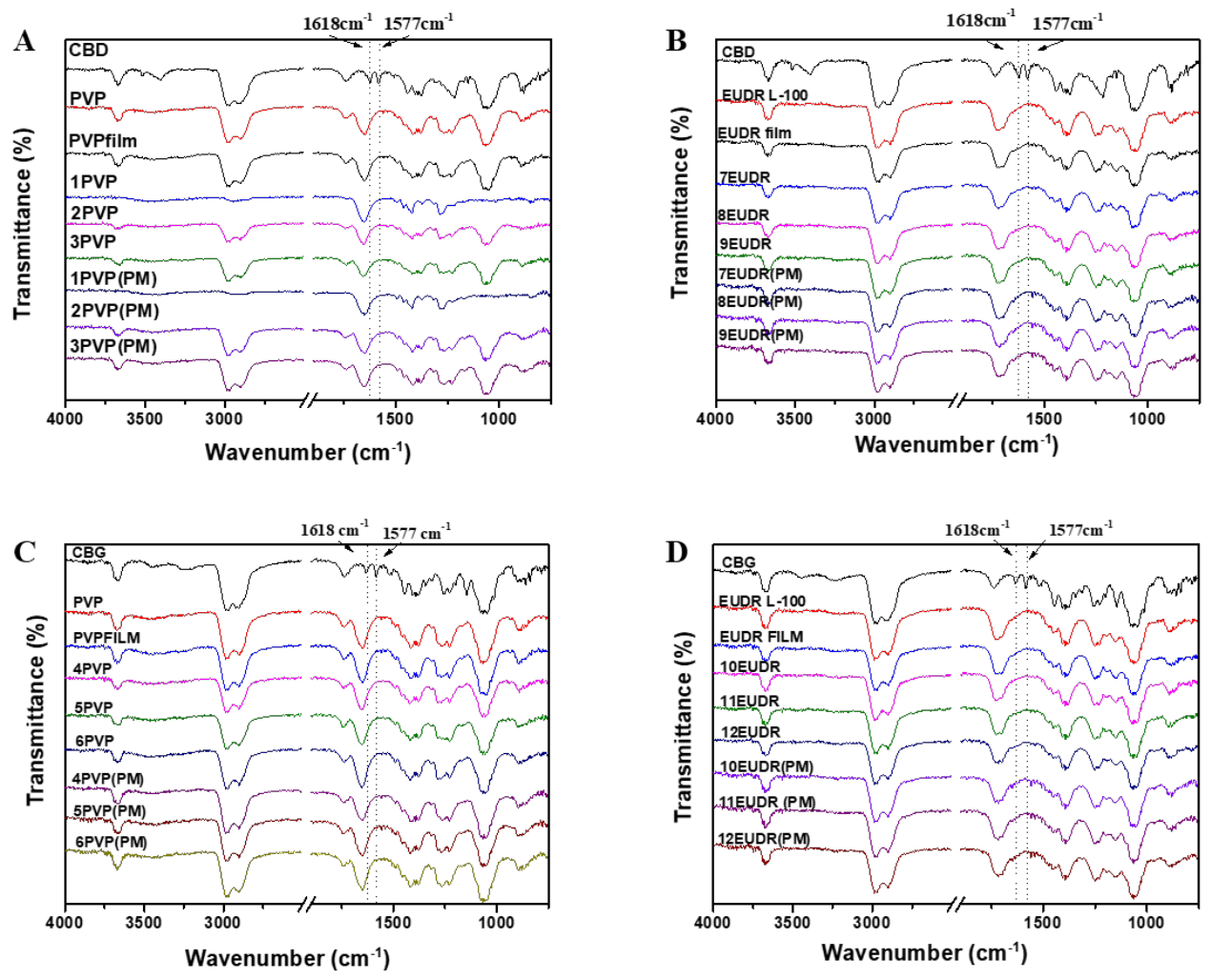

FIGURE 3 

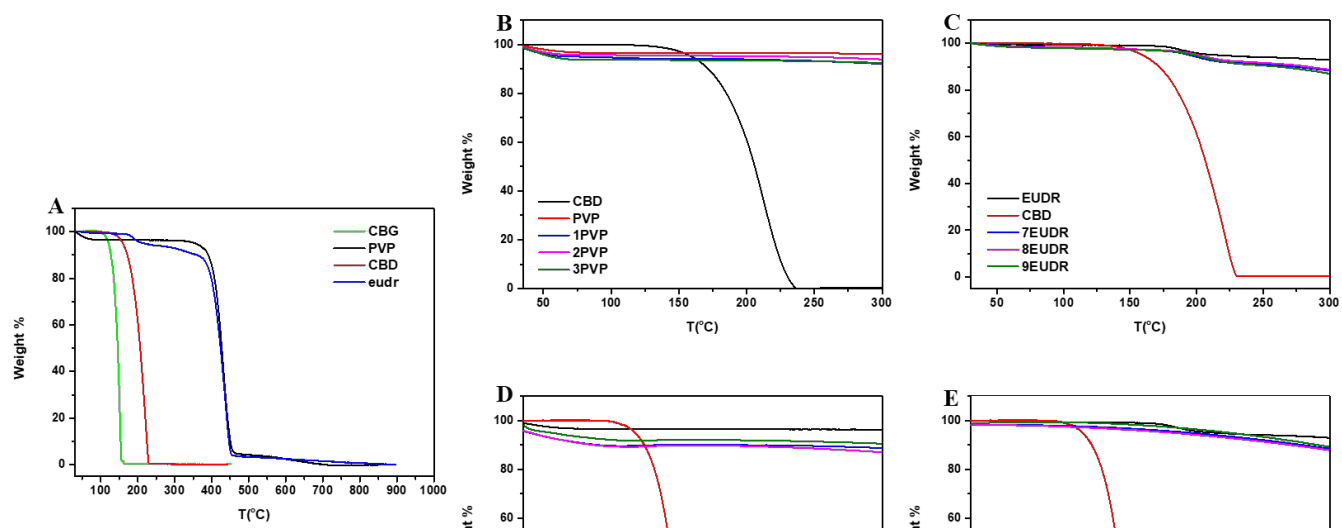

797
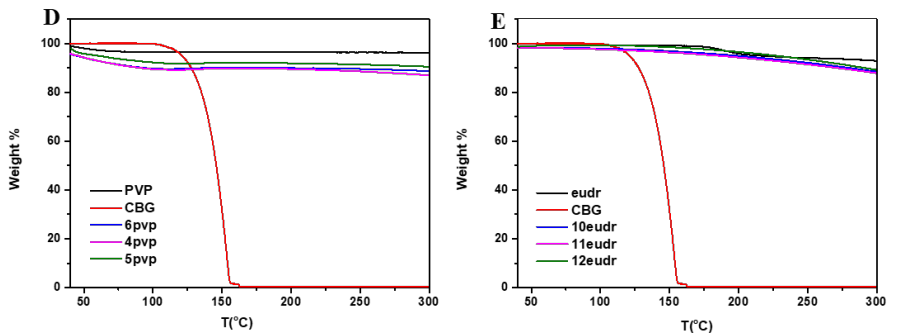

798

799

800

801

802

803

804

805

806

807

808

809

810

811

812

813

814

815

816

817

818

819

820

FIGURE 4 

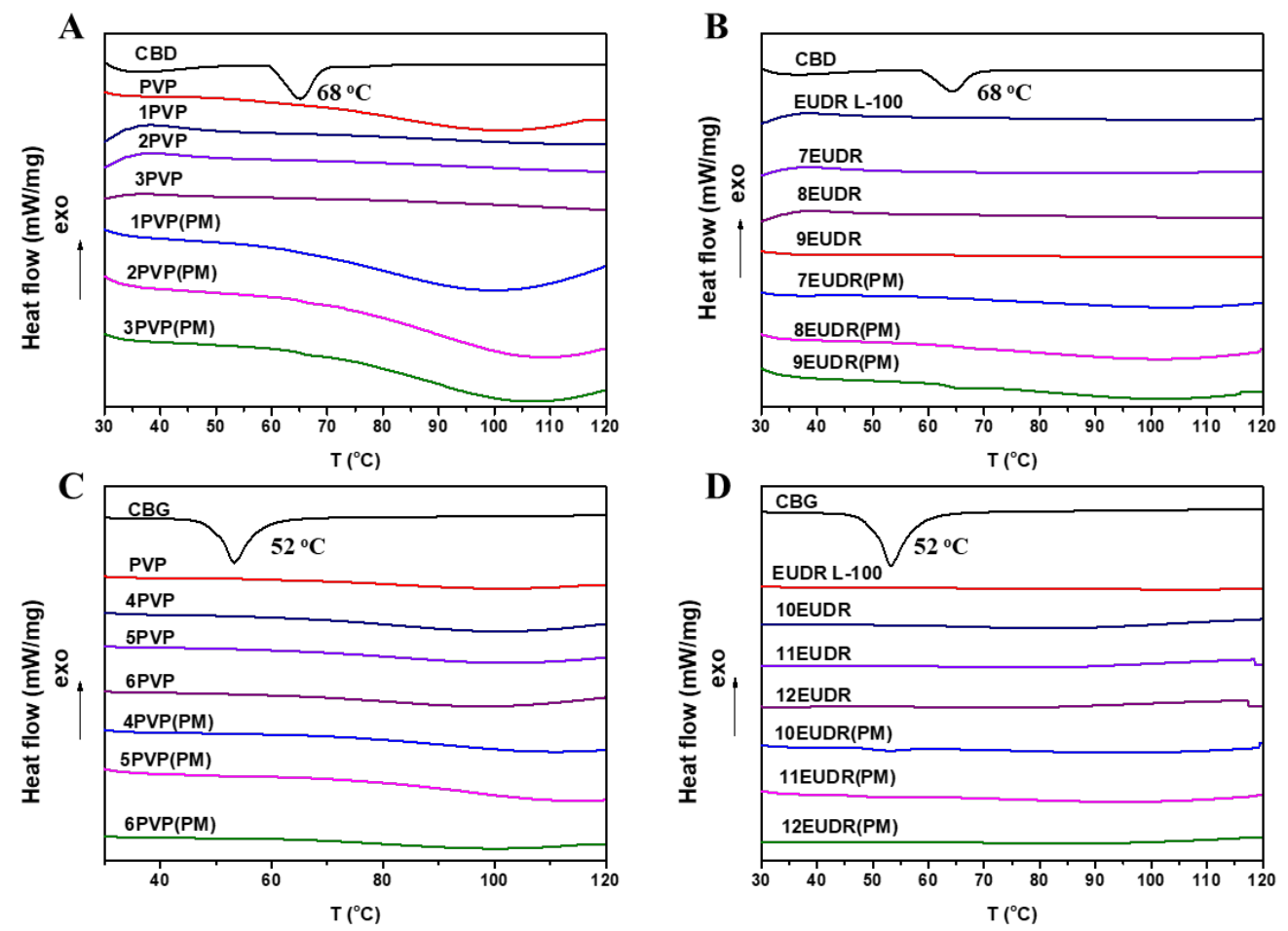

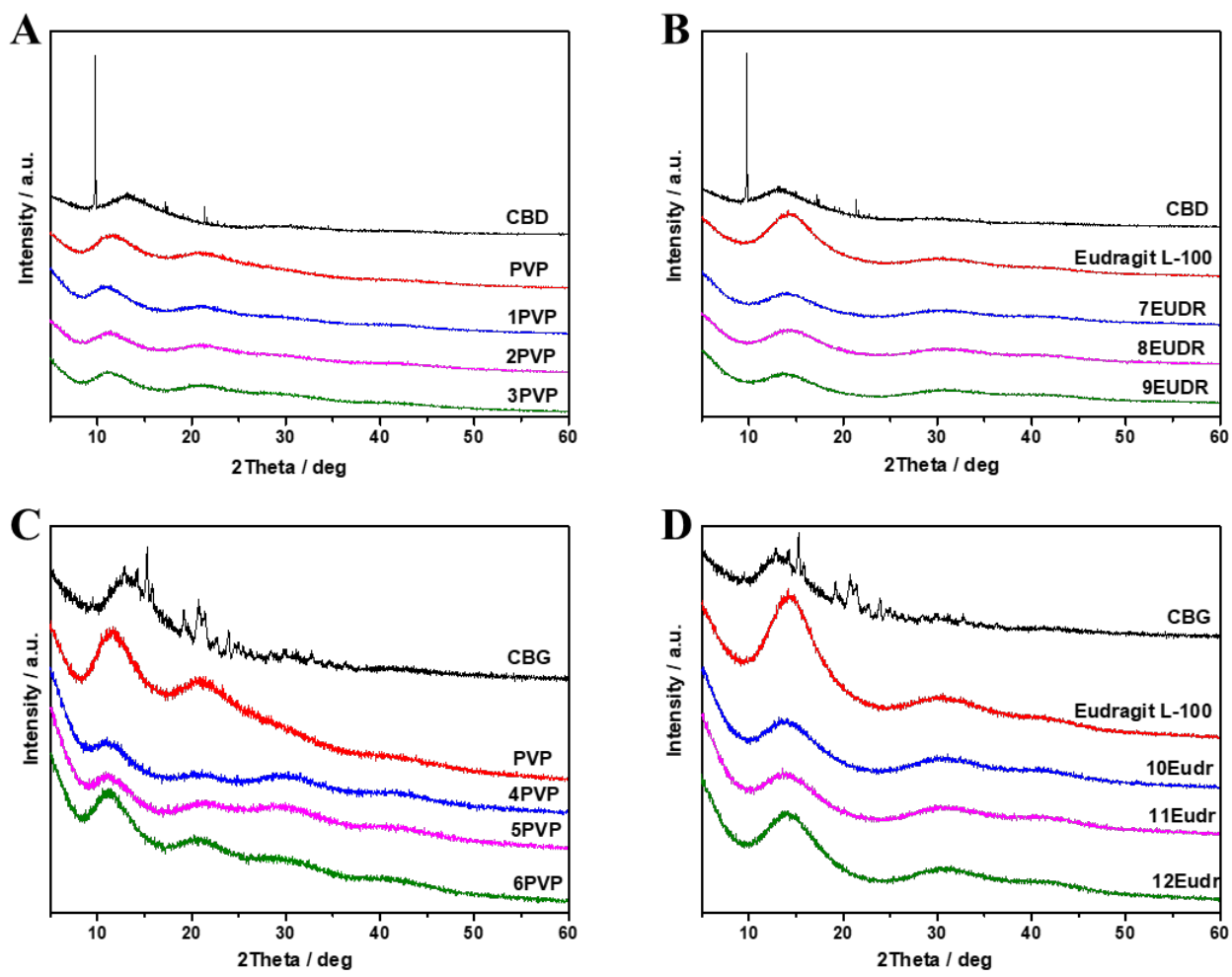

841

842

843

844

845

846

847

848

849

850

851

852

853

854

855

856

857

858

859 
FIGURE 6
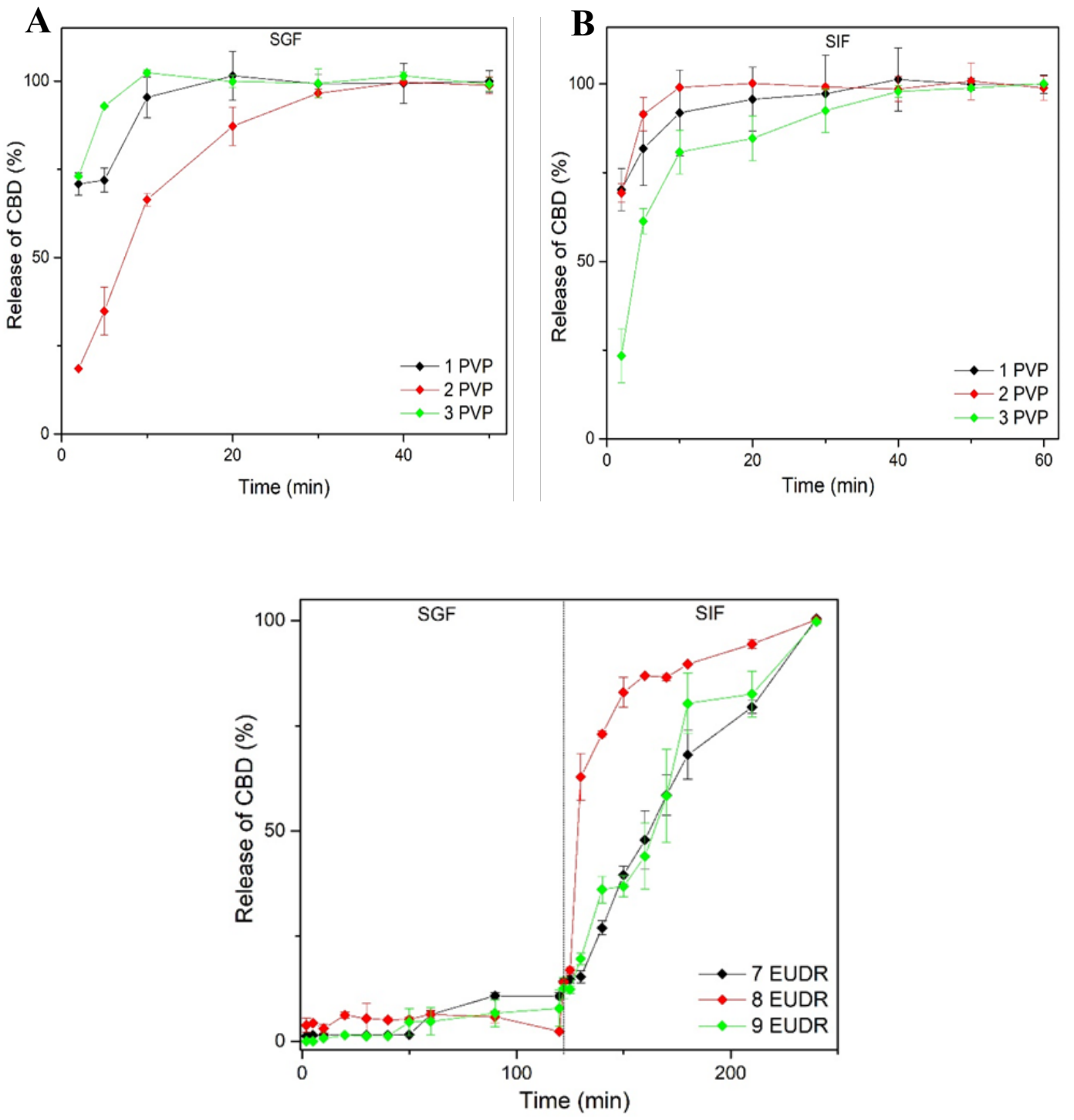

861

862

863

864

865

866

867

868

869

870

871

872 
873 FIGURE 7

874

875

876

877

878

879

880

881

882

883

884

885

886

887

888

889

890

891

892
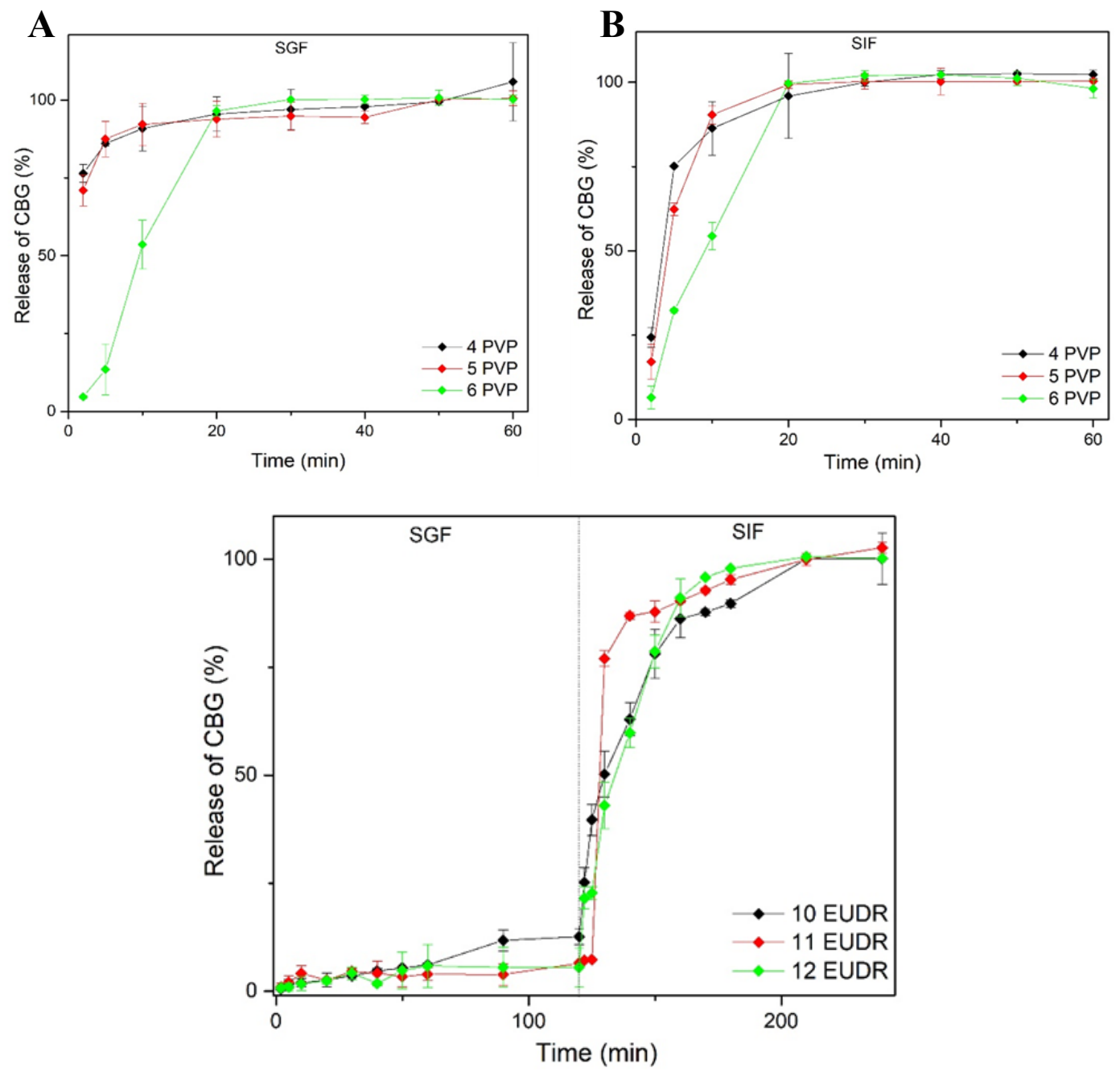

893

894

895

896

897

898

899

900

901

902

903

904

905

906 
FIGURE 8

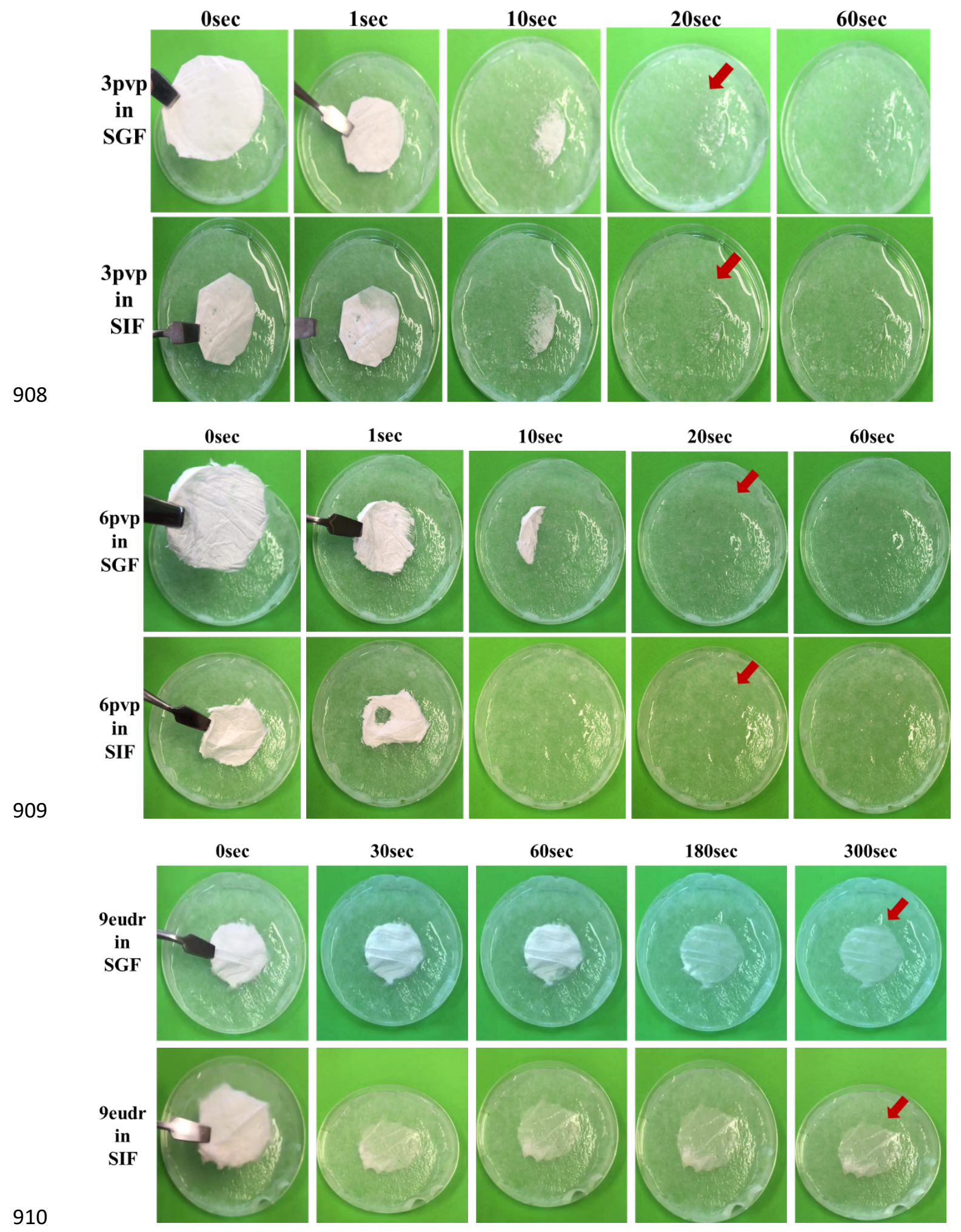




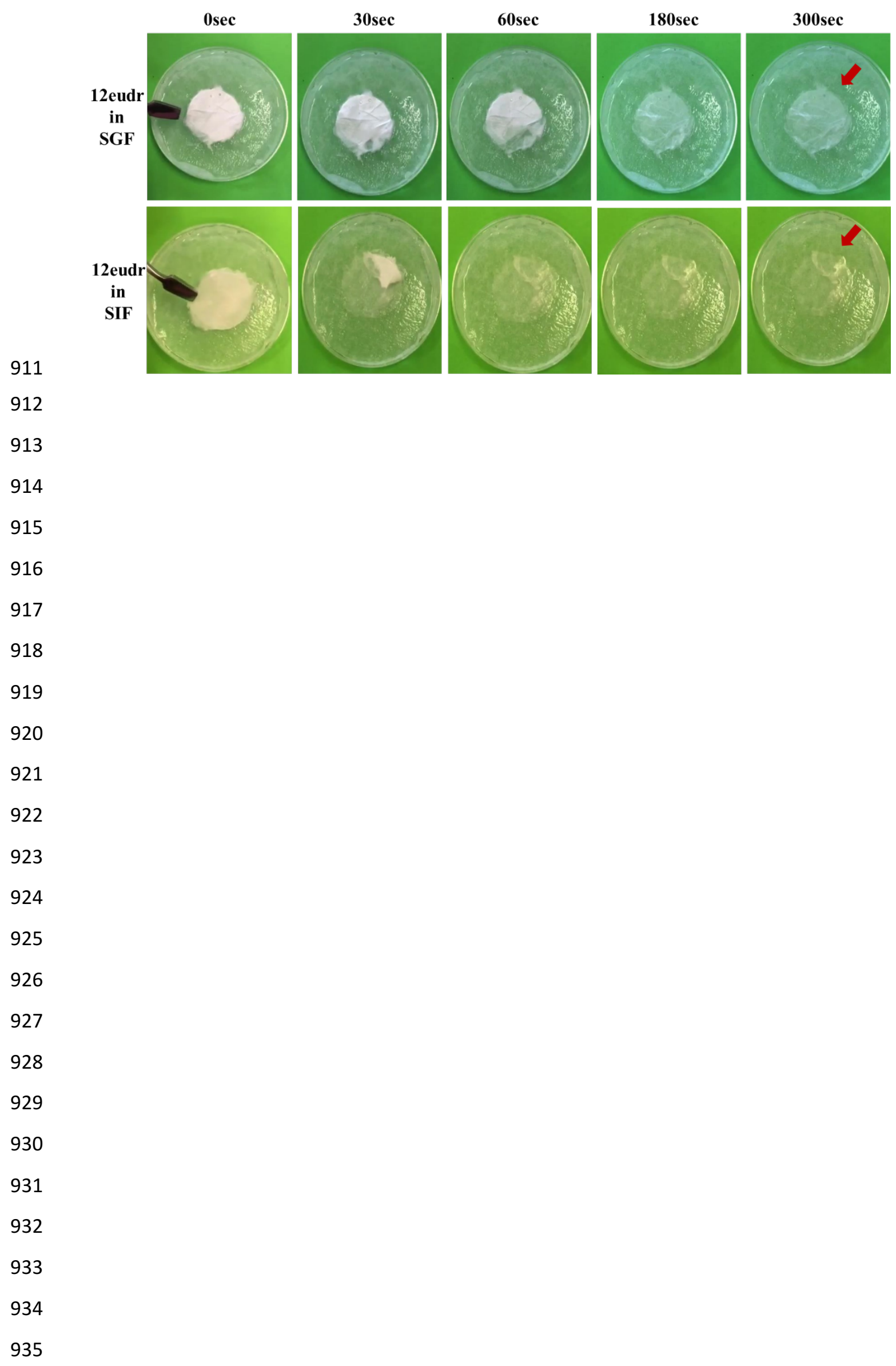


FIGURE 9
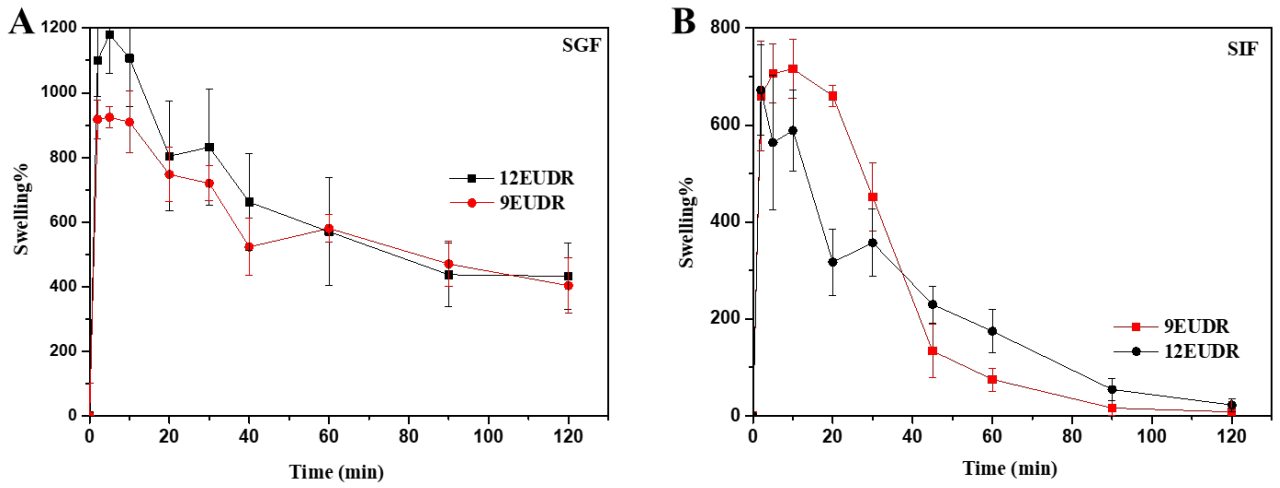

937 